\title{
Estabilização de Solos com um Aditivo a Base de Enzimas para fins Rodoviários
}

\section{Soil Stabilization with an Enzymatic Additive for Pavings}

\author{
${ }^{1}$ Lucas Ribeiro dos Santos, ${ }^{2}$ Flavio Alessandro Crispim ${ }^{3}$ Philipe Razia Del Paulo \\ ${ }^{1}$ Doutorando no Programa de Pós-Graduação em Engenharia de Estruturas, Universidade Federal de Minas \\ Gerais, Av. Antônio Carlos, 6627 - Escola de Engenharia - Bloco 1 - $4^{\circ}$ andar, sala 4215, Pampulha, Belo \\ Horizonte - MG (luccasrsantos@gmail.com.br) \\ ${ }^{2}$ Doutor em Engenharia Civil, Professor Adjunto da Faculdade de Ciências Exatas e Tecnológicas - FACET da \\ Universidade do Estado de Mato Grosso (flavio.crispim@unemat.br) \\ ${ }^{3}$ Engenheiro Civil e de Segurança do Trabalho, Rodovia MT-130, KM 30, Zona Rural, Primavera do Leste - MT \\ (philipe000@gmail.com)
}

\begin{abstract}
RESUMO: As soluções estabilizadoras de solos a base de enzimas surgiram recentemente no cenário da engenharia rodoviária brasileira, oferecendo aos engenheiros novas possibilidades na construção e recuperação de rodovias. Este artigo apresenta os resultados experimentais de uma pesquisa elaborada com o aditivo constituído pela solução enzimática ESS-X a fim de verificar a sua viabilidade técnica para a aplicação em solo típico da região norte do estado de Mato Grosso. O solo analisado é classificado pela American Association of State Highway and Transportation Officials-Transportation Research Board (TRB-AASHTO) e pela Unified Soil Classification System (UCSC) como sendo solo silto-argiloso A-4 (7) e como solo ML, respectivamente. Realizou-se análise experimental para a avaliação da resistência mecânica do solo com três dosagens do aditivo: 1/150 (recomendada pelas especificações técnicas), 1/300 e 1/600. Foram realizados os ensaios de resistência à compressão não-confinada (RCNC), absorção de água e Índice de Suporte Califórnia (ISC). Percebeu-se que no ensaio de RCNC que o aditivo influenciou de forma considerável as propriedades do solo, elevando em cerca 3,6 vezes a resistência mecânica do mesmo na dosagem 1/150, se comparado ao solo na condição natural. Quanto à absorção de água, o aditivo não proporcionou alteração relevante nessa propriedade, porém ofereceu maior estabilidade aos corpos de prova para a dosagem 1/150. Por fim, os ensaios de ISC indicaram que aditivo não ofereceu bons resultados para a elevação da capacidade de suporte do solo em condições submersas, se comparado ao solo sem aditivo.
\end{abstract}

Palavras Chave: Aditivo orgânico; Resistência do solo; Solos tropicais; Enzimas.

ABSTRACT: The enzymatic additives have recently emerged on the scene of road engineering, engineers offering new possibilities in the construction and rehabilitation of Brazilian highways. This article discusses the experimental results of a survey conducted with the enzymatic additive ESS-X in order to verify its technical feasibility for use in typical soil of the northern region of Mato Grosso state, Brazil. The analyzed soil is classified by American Association of State Highway and Transportation Officials-Transportation Research Board (TRB - AASTHO) and by Unified Soil Classification System (UCSC) as silty-clay soil A-4 (7) and ML, respectively. The experimental analysis was performed for evaluation of the mechanical strength of the soil with three dosages of the additive, 1/150 (recommended by technical specifications), 1/300 and 1/600. Unconfined Compressive Strength (UCS), water absorption and California Bearing Ratio (CBR) tests were performed. It was noticed in the UCS test that in the soil properties were influenced considerably by the enzymatic additive, raising about 3.6 times its resistance, when compared to soil under natural condition. As for water absorption additive showed no considerable change but offered a more stability in the arrangements of soil particles to the specimens at a dose 1/150. Finally, in the results of the ISC tests the additive did not offer good results for the increase of the support capacity under submerged conditions, if compared to the soil in the condition without the additive.

Keywords: Organic additive; Soil resistance; Tropical soil; Enzymes.

\section{INTRODUÇÃO}

Nas últimas décadas, houve um aumento significativo na construção e recuperação de rodovias brasileiras, havendo um expressivo impacto econômico e ambiental nos canteiros de obras rodoviárias. Em condições normais, tanto a obra em si quanto a extração de materiais virgens e granulares, causam impacto na natureza e tem elevados custos de transporte e de licenciamento ambiental. 
Nem sempre o solo natural apresenta características técnicas suficientes para atender os requisitos normativos, sendo nestes casos necessária à sua substituição ou uma intervenção a fim de melhorar suas características físico-mecânicas. A substituição do solo implica em aumento dos custos de construção e do impacto ambiental da obra, podendo-se citar: a remoção do material, extração de materiais de outras áreas (muitas vezes em locais distantes), aumento das distâncias de transporte e a definição e o tratamento de locais para bota-foras. Dessa forma, surge como alternativa a utilização de solos locais que submetidos a processos de estabilização, tem suas características físico-mecânicas melhoradas, podendo então ser enquadrados nas especificações técnicas das normas vigentes.

$\mathrm{Na}$ busca por novas tecnologias que propiciem melhoras nas propriedades de engenharia dos solos, os aditivos compostos por soluções enzimáticas atuam como agentes de estabilização de solos, fornecendo uma melhor estabilidade dos agregados em conjunto com as partículas do solo utilizados em base de rodovias. Esses aditivos despontam na engenharia rodoviária como uma alternativa bastante interessante nos quesitos de sustentabilidade e economia, visto que são ecológicos e não agridem o meio ambiente. Portanto, conhecer o potencial desses aditivos ou propor novas metodologias de ensaio capaz de avaliar a influência desses agentes estabilizadores em todos os tipos de solos têm sido o maior desafio dos pesquisadores nas últimas décadas.

Os estudos recentes confirmam a eficiência desses aditivos compostos por soluções enzimáticas na estabilização de solos, podendo-se mencionar os trabalhos de Malko et al. (2014), Saini (2015), Jadhav et al. (2016), Rafique et al. (2016), Eujine et al. (2017a) e Eujine et al. (2017b). Em todos esses estudos utilizou-se a solução Terrazyme constituída por enzimas extraídas da cana-de-açúcar. Outros agentes estabilizadores de solo também têm sido avaliados por outros pesquisadores, podendo-se mencionar a enzima urease e a solução enzimática Eko-Soil, apresentadas nos trabalhos de Carmona et al. (2017) e Renjit et al. (2017), respectivamente.

Os resultados de Rafique et al. (2016) foram bastante promissores no quesito de elevação da capacidade de suporte do solo, i.e., ISC (Índice Suporte Califórnia). Na dosagem 1/400 (proporção aditivo/água), esses autores observaram uma elevação nos valores do ISC de 10,47 para 16,28, sinalizando uma elevação de 55\% da capacidade de suporte. Com esse nível de melhora, segundo os autores, haveria uma redução de custo entre $15-20 \%$ na construção de novas rodovias e uma redução de custo de $60 \%$ na manutenção das rodovias quando comparadas com rodovias sem estabilizadores de solo.

Por outro lado, a grande maioria dos engenheiros rodoviários ainda usam produtos somente à base de cal para estabilização de solos. Existem perigos ambientais importantes associados ao uso desses produtos, tais como a lixiviação dos compostos da cal para o lençol freático, ocasionando a alteração na microflora do solo, a elevação do $\mathrm{pH}$ da água com consequente impacto na vida aquática (Rafique et al., 2016). Estudos comparativos de Eujine et al. (2017a) e Eujine et al. (2017b) relacionados à substituição da cal por solução a base de enzimas na estabilização dos solos revelaram melhoria na capacidade de suporte dos solos. Na proporção de $70 \mathrm{~mL} / \mathrm{m}^{3}$ (volume de aditivo $/ \mathrm{m}^{3}$ de solo), Eujine et al. (2017a) observaram elevação de três a seis vezes nos valores de ISC sob condições secas de um solo estabilizado com cal com adição da enzima e de solo estabilizado somente com a enzima, se comparado com o solo na condição natural, respectivamente.

Um aditivo ainda pouco estudado é ESS-X composto por enzimas produzidas a partir de produtos açucarados como a cana de açúcar. O ESS-X já foi utilizado comercialmente no estado de Mato Grosso nas rodovias MT-486: "Rodovia da União" - Primavera do Leste à vila União e na "Rodovia Um novo tempo" - Partindo da Rod. MT-486 sentido Fazenda Galheiros. As informações sobre o uso do produto no Brasil ainda se resumem as do 
fabricante ou de usuários baseados em resultados práticos, havendo necessidade de avaliar tecnicamente as suas qualidades (eficiência) em termos de estabilização com solos locais.

Em grande parte da região norte do estado de Mato Grosso há carência de materiais granulares, sendo comum nas obras de pavimentação o emprego de cascalho laterítico, porém sua extração causa impacto ambiental considerável pelo fato das jazidas se encontrarem em áreas próximas de rios e de preservação. Além disso, um grande volume de solo que se encontra sobre a camada de cascalho é descartado durante o processo de extração (Dalla Roza e Crispim, 2013).

Neste contexto, o presente trabalho objetiva avaliar a influência nas propriedades de engenharia de um solo típico da região com a aplicação do aditivo constituído por uma solução estabilizadora de solos ESS-X, buscando uma solução que alie o uso de um solo antes descartado e um aditivo de baixo impacto ambiental.

\section{MATERIAIS E MÉTODOS}

\subsection{Materiais}

\subsubsection{Solo}

$\mathrm{Na}$ realização desta pesquisa foi utilizada uma amostra de solo coletada por Simioni (2011), em profundidade entre $0,20 \mathrm{~m}$ e $0,40 \mathrm{~m}$. O local da coleta está localizado nas

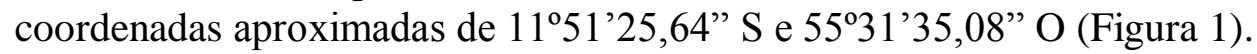

Figura 1 - Local de coleta de solo

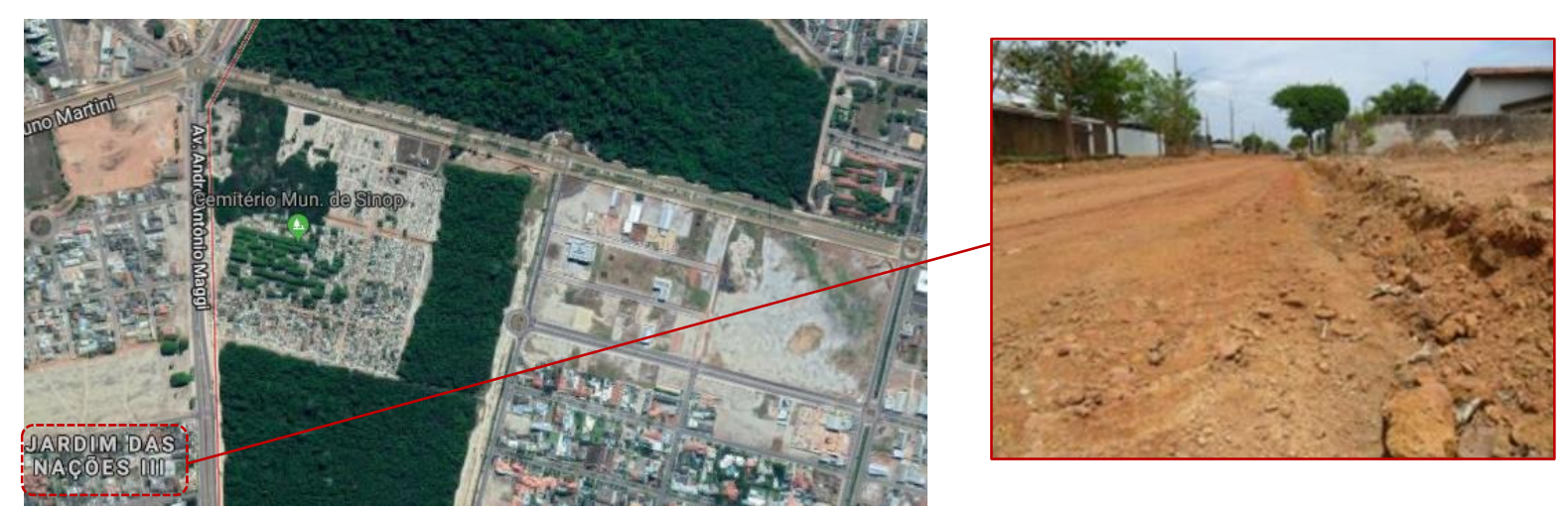

Fonte: Adaptado de Simioni (2011) e Google Earth (2018).

Trata-se de um solo classificado como ML pelo USCS (Unified Soil Classification System) e como A-4 (7) pela AASHTO-TRB (American Association of State Highway and Transportation Officials-Transportation Research Board), sendo então definido como solo silto-argiloso, com baixa capacidade de suporte com vistas a sua utilização para subleito de rodovias.

Simioni (2011) realizou a caracterização geotécnica da amostra de solo pesquisado. Os valores de limite de liquidez do solo (LL), índice de plasticidade (IP), teor de umidade $\left(w_{o t}\right)$ e peso específico seco máximo do solo $\left(\gamma_{d \text { max }}\right)$ podem ser visualizados na Tabela 1 .

Tabela 1 - Caracterização geotécnica do solo

\begin{tabular}{ccccccccc}
\hline \multicolumn{2}{c}{ Areia (\%) } & Silte + argila & LL & IP & $w_{o t}$ & $\gamma_{\mathrm{d} \max }$ & $\begin{array}{c}\text { ISC } \\
\% \\
\text { Grossa }\end{array}$ \\
\hline 2 & 0 & 28 & 70 & 32 & 6 & 23,40 & 14,89 & 12,62 \\
\hline
\end{tabular}

Fonte: Simioni (2011). 
SANTOS, LUCAS R.; et al; Estabilização de Solos com um Aditivo a Base de Enzimas para fins Rodoviários. E\&S - Engineering and Science, 2018, 7:3.

\subsubsection{Aditivo}

Segundo as especificações técnicas do produto, o ESS-X é um aditivo que não possui reagentes com compostos orgânicos voláteis, fazendo com que o mesmo se adeque facilmente às condições naturais do solo. Seu efeito de estabilização é mais pronunciado com o decorrer do tempo, não surgindo o "endurecimento das camadas" de forma instantânea, mas sim conforme o decorrer dos dias. De acordo as especificações técnicas do fabricante (OTP International), o aditivo apresenta melhor eficácia com valores do Limite de Liquidez (LL) inferior a $40 \%$ e o Índice de Plasticidade (IP) entre 5 a $18 \%$.

$\mathrm{O}$ aditivo possui a aparência de um líquido acastanhado com odor doce leve. É composto por enzimas produzidas a partir de produtos açucarados como a cana de açúcar. $\mathrm{Na}$ Tabela 2 estão algumas informações sintetizadas do produto.

Tabela 2 - Descrição física e propriedades do ESS-X

\begin{tabular}{cc}
\hline Ponto de ebulição & $212^{\circ} \mathrm{F}\left(100^{\circ} \mathrm{C}\right)$ \\
Densidade especifíca & $1,07 / 25^{\circ} \mathrm{C}$ \\
Ponto de congelamento & $0^{\circ} \mathrm{C}$ \\
Solubilidade em água & Completa \\
Compostos orgânicos voláteis & Nenhum \\
$\mathrm{pH}$ & entre 3,2 a 5,1 \\
\hline
\end{tabular}

Fonte: OTP International (2013).

\subsection{Métodos}

As amostras de solo foram preparadas conforme as prescrições da NBR 6457 (ABNT, 1986) em três dosagens diferentes do ESS-X, sendo elas: 1/150 (recomendado nas especificações técnicas do produto), 1/300 e 1/600. Conforme as especificações técnicas, essas dosagens também podem ser apresentadas em função da proporção do aditivo em $1 \mathrm{~m}^{3}$ de solo, sendo assim, as dosagens, 1/150, 1/300 e 1/600 equivalem a uma diluição de $33 \mathrm{~mL} / \mathrm{m}^{3}, 16,66 \mathrm{~mL} / \mathrm{m}^{3}$ e $8,33 \mathrm{~mL} / \mathrm{m}^{3}$.

Os corpos de prova foram compactados na energia do Proctor Normal seguindo as recomendações da NBR 7182 (ABNT, 1986). Também foi verificada a influência do aditivo no solo sobre o teor de umidade ótimo $\left(w_{o t}\right)$ peso específico seco máximo $\left(\gamma_{\text {dmax }}\right)$ obtendo a curva de compactação das misturas solo-aditivo para cada teor de aditivo utilizado.

$\mathrm{O}$ efeito do aditivo no solo foi avaliado a partir do ensaio de RCNC (Resistência a compressão não-confinada) dos corpos de prova compactados com as misturas solo-aditivo. Os ensaios para determinação da RCNC foram realizados de acordo com a NBR 12770 (ABNT, 1996), considerando períodos de cura de 7 e 28 dias. Foram realizadas três repetições para cada teor de aditivo como mostrado na Figura 2.

Figura 2 - Esquema do ensaio de resistência à compressão não-confinada
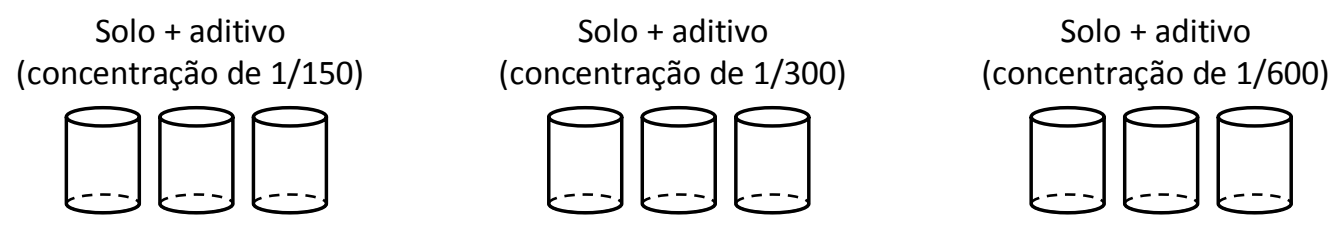

Com a finalidade de verificar a influência do aditivo na capacidade do solo em absorver água, realizou-se ensaio de absorção de água no solo seguindo os critérios da 
SANTOS, LUCAS R.; et al; Estabilização de Solos com um Aditivo a Base de Enzimas para fins Rodoviários. E\&S - Engineering and Science, 2018, 7:3.

NBR 13555 (ABNT, 1996). Foram realizadas duas repetições para cada teor de aditivo como mostrado na Figura 3.

Figura 3 - Esquema do ensaio de absorção de água

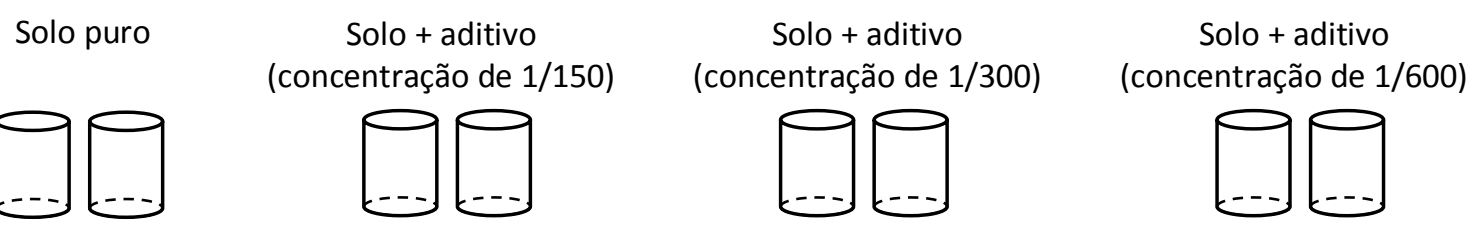

\section{ANÁLISE E DISCUSSÃO DOS RESULTADOS}

Na Figura 4 são apresentadas as curvas de compactação do solo natural e do solo com aditivo na concentração 1/150. Essas curvas foram elaboradas com o objetivo de verificar se o aditivo, na concentração mais elevada, influenciaria o parâmetro ótimo de compactação do solo.

Figura 4 - Curva de compactação do solo na condição natural e solo+aditivo 1/150

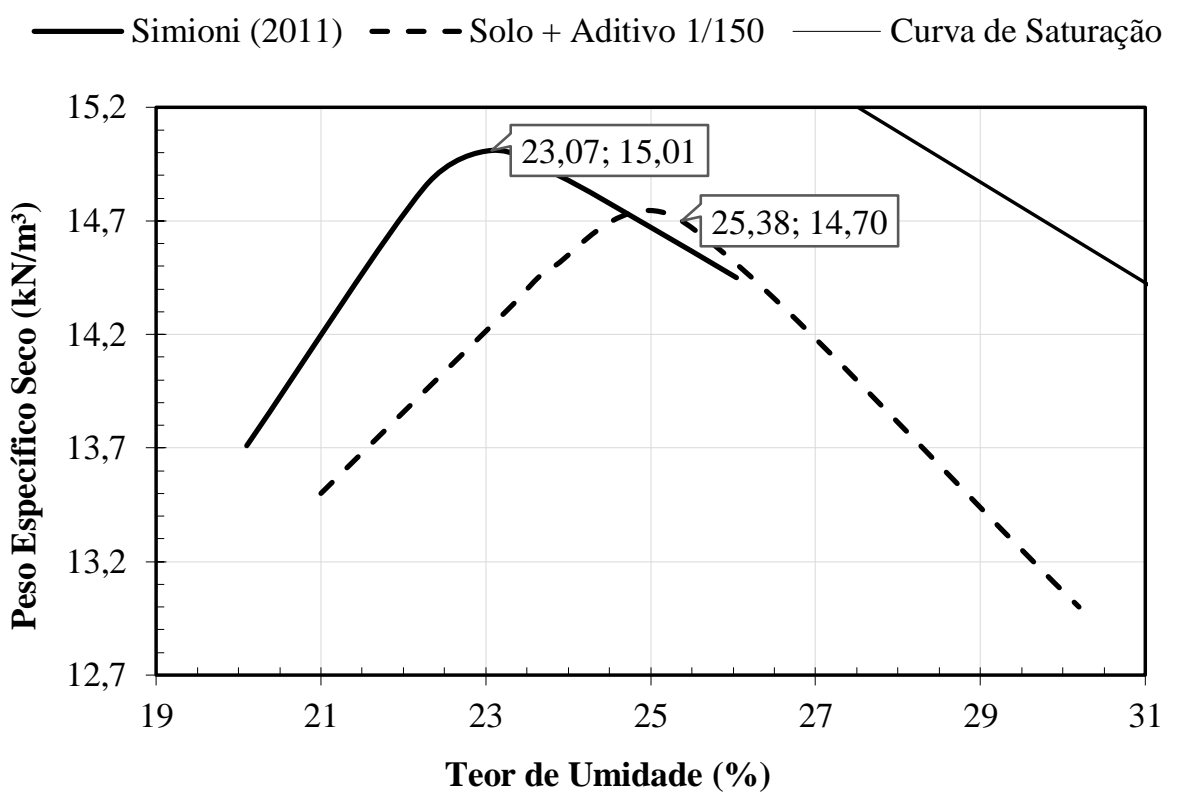

A curva de compactação obtida para o solo na condição natural apresentou valores de teor de umidade ótimo $\left(w_{o t}\right)$ e peso específico seco máximo $\left(\gamma_{d \max }\right)$ iguais a $23,07 \%$ e $15,01 \mathrm{kN} / \mathrm{m}^{3}$, respectivamente. Em relação a curva de compactação obtida para o solo com o aditivo, esses valores foram iguais a $25,38 \%$ e $14,70 \mathrm{kN} / \mathrm{m}^{3}$, respectivamente.

Observa-se na Figura 4 que houve um pequeno acréscimo no teor de umidade de $23,07 \%$ para $25,38 \%$, uma diferença menor que $2,50 \%$. A adição do aditivo teve efeito semelhante ao observado na adição de finos (cal, cimento, etc) ao solo, ou seja, aumento no $w_{o t}$ e redução no $\gamma_{d \max }$. Os demais teores não foram testados, pois, espera-se que as curvas resultantes sejam intermediárias entre as curvas do solo natural e do solo com aditivo na concentração 1/150. A variação observada nos parâmetros de compactação está dentro das faixas admitidas pelos órgãos rodoviários de $+/-2 \%$ para $w_{o t}$ e de $+/-0,5 \%$ para $\gamma_{d \text { max }}$. Em 
decorrência disso, optou-se nesse estudo adotar os parâmetros de compactação do solo puro para a execução dos ensaios.

\subsection{Resistência à compressão não-confinada $(R C N C)$}

Na Figura 5, por meio do eixo vertical esquerdo, são apresentados os resultados do ensaio de RCNC obtidos para os períodos de cura de 7 e 28 dias e, por meio do eixo vertical direito, apresentam-se as relações percentuais entre os valores de RCNC com aditivo e os valores de RCNC do solo puro, em ambos os casos, em função das dosagens propostas neste estudo.

Figura 5 - RCNC de acordo os períodos de cura e relação percentual solo+aditivo/solo puro

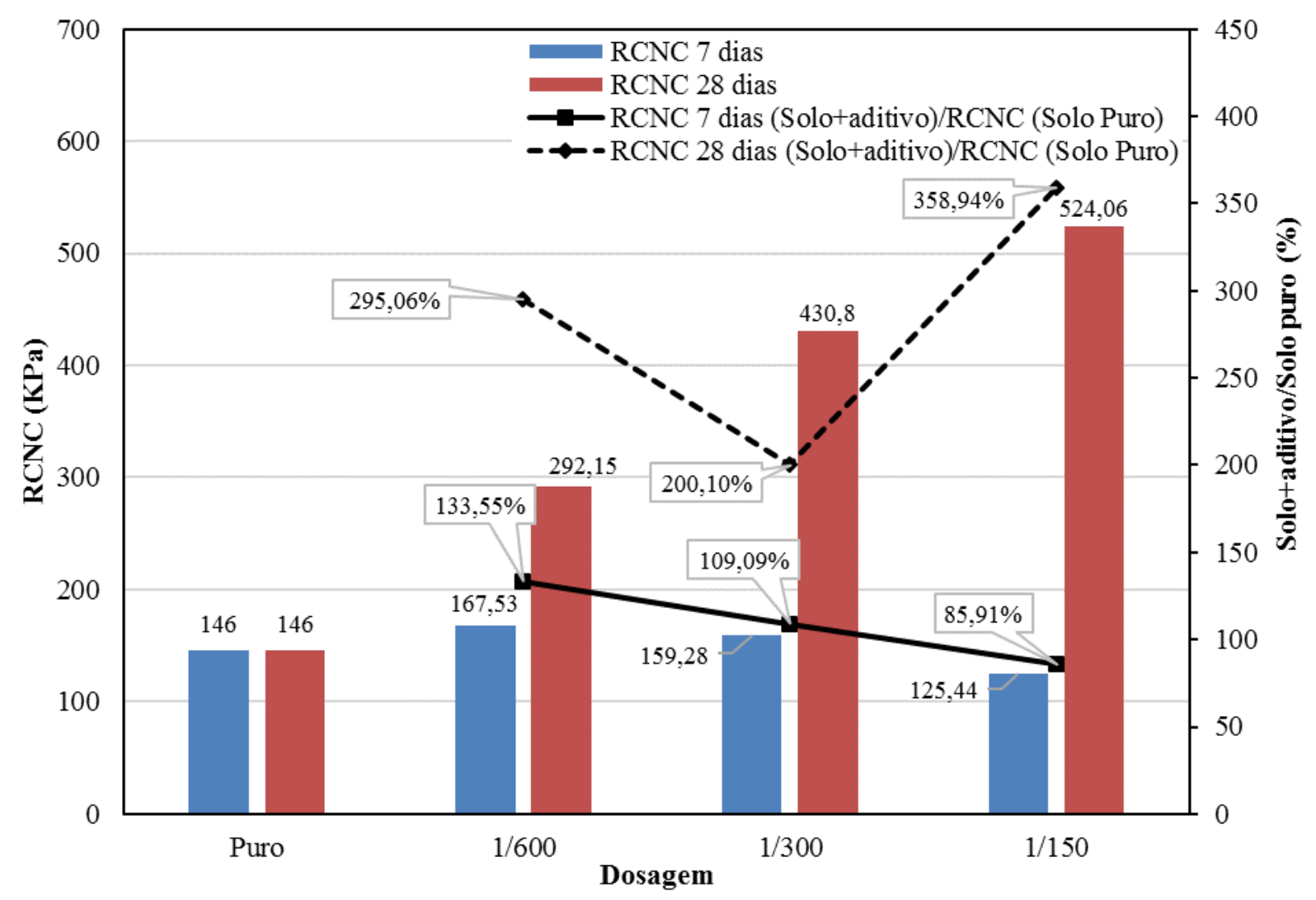

Observa-se na Figura 5 que o solo estudado apresentou comportamento peculiar quanto a RCNC para os 7 dias de cura, onde se nota que os valores de resistências foram inversamente proporcionais ao teor de aditivo. Acredita-se que essa redução esteja associada a alguma reação química propiciada pelas enzimas presentes no aditivo que enfraqueceram a tensão de contato na interface das partículas do solo e, após certo tempo, forneceu uma elevação nesta tensão de contato, melhorando a estabilidade entre os grãos do solo.

Aos 28 dias, o comportamento foi o observado em outros estudos que indicam que quanto maior o teor de aditivo, maior a resistência observada na amostra. Comportamento semelhante foi observado para o aditivo Terrazyme analisado por Eujine et al. (2017b) em três dosagem diferentes $\left(70 \mathrm{~mL} / \mathrm{m}^{3}, 80 \mathrm{~mL} / \mathrm{m}^{3}\right.$ e $\left.90 \mathrm{~mL} / \mathrm{m}^{3}\right)$ no qual observou-se que quanto maior os teores de aditivo, mais pronunciados foram os valores das resistências mecânicas encontrados, ocorrendo porém este comportamento nos períodos de cura iguais a 4,8 e 12 dias. 
Ao se analisar as relações percentuais entre a RCNC das misturas e a RCNC do solo puro, nota-se que o solo perdeu resistência na dosagem 1/150 enquanto que nas dosagens 1/300 e 1/600, o solo apresentou elevação na resistência mecânica para o período de 7 dias. No período de cura de 7 dias, os acréscimos de resistência do solo com aditivo em relação ao solo puro foram na ordem de 109,09\% e 133,55\% para as concentrações 1/300 e 1/600, respectivamente. Por outro lado, na concentração de 1/150, o solo perdeu resistência atingindo apenas $85,91 \%$ da resistência do solo puro. Este comportamento não foi observado com a solução estabilizadora Terrazyme analisada nos estudos Eujine et al. (2017a) e Eujine et al. (2017b).

Aos 28 dias, na dosagem 1/150 houve acréscimo de 358,94\% e, na dosagem 1/600 a resistência do solo foi aumentada em $295,06 \%$. Nota-se também que a dosagem 1/300 foi a que apresentou menor acréscimo da resistência, de 200,10\%. Constata-se, portanto, que o acréscimo ou a diminuição da resistência neste tipo solo não foi diretamente proporcional a dosagem da solução estabilizante para os 28 dias de cura.

Diante dos resultados encontrados, é possível inferir que o efeito imediato do aditivo é pequeno, mas expressivo com o passar do tempo, atingindo resistências significativas para idades próximas de 30 dias, fato este relatado nas especificações técnicas do produto.

\subsection{Absorção de água}

Na Figura 6 são apresentados os resultados do ensaio de absorção de água das misturas de solo-aditivo analisadas. Os corpos de prova ficaram em câmara úmida durante 9 dias.

Figura 6 - Absorção de água em função do teor de aditivo

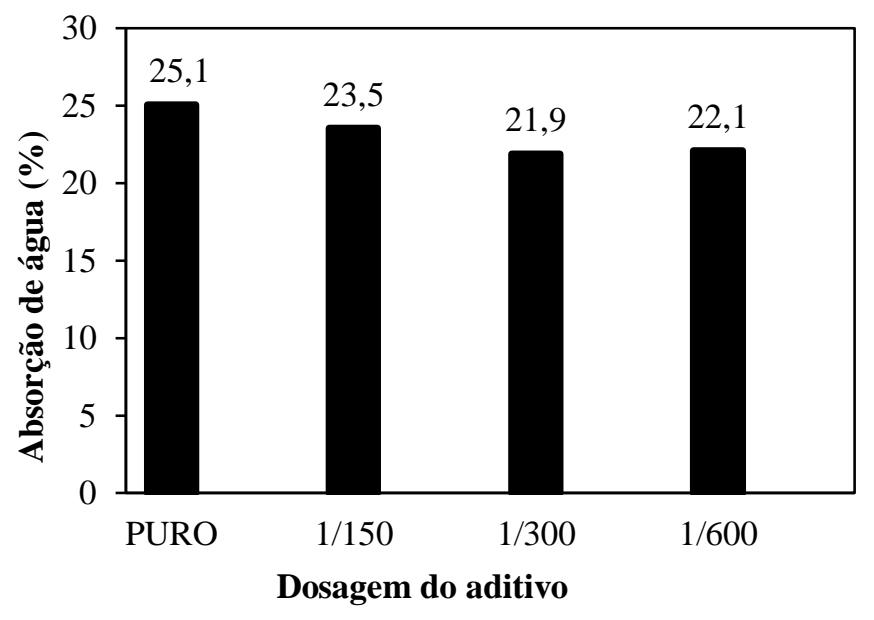

O teor de absorção de água nos corpos de prova em relação ao de referência (puro) foi inferior a $12,7 \%$ com o acréscimo de aditivo, sendo considerada a redução de baixa magnitude. Porém, nota-se a maior estabilidade do solo com a maior proporção do aditivo, conforme ilustrado na Figura 7.

Percebe-se que com o aditivo na dosagem 1/300 houve menor estabilidade das partículas do solo nas bordas dos corpos de prova, resultando em bordas suavizadas (Figura $7 b$ ), enquanto que na dosagem $1 / 150$ as bordas permaneceram bem definidas e estáveis (Figura 7a). 
Figura 7 - (a) Corpo de prova 1/150 após ensaio de absorção; (b) Corpo de prova 1/300 após ensaio de absorção

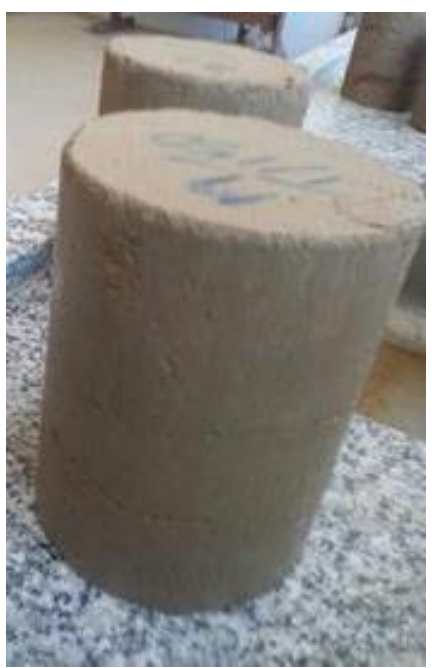

(a)

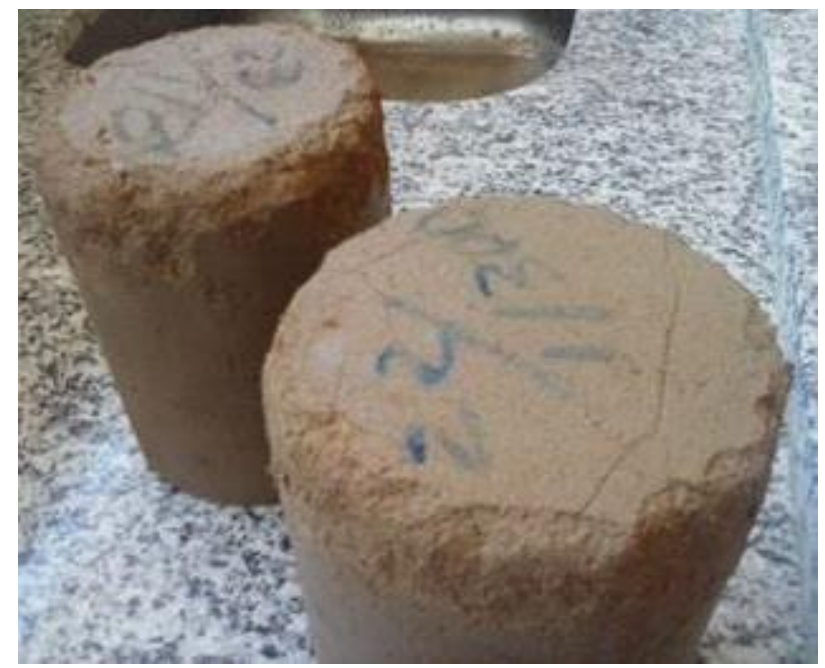

(b)

\section{3 Índice de Suporte Califórnia - ISC}

O valor do ISC obtido por Simioni (2011) para o solo foi igual a 12,62\%. Os resultados obtidos para o ensaio de ISC na dosagem mais elevada (1/150) são apresentados na Figura 8. Ressalta-se que que os corpos de prova, ISC1 e ISC2, permaneceram em período de cura por 26 dias e imersos em água por 4 dias.

Figura 8 - ISC do Solo utilizando aditivo na dosagem 1/150

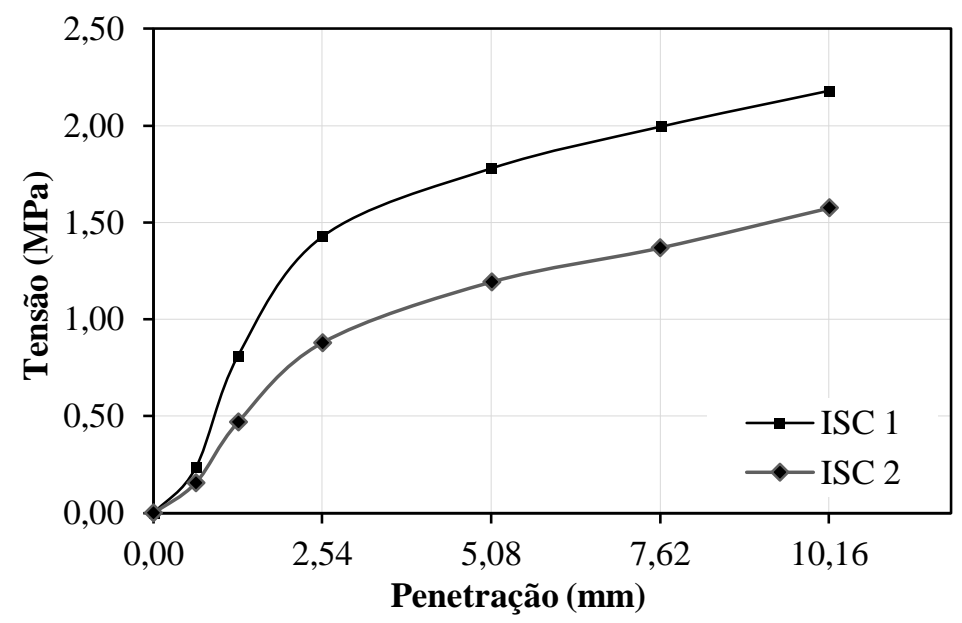

O solo apresentou $I S C_{m e d}$ igual a $18,60 \%$, resultado próximo do ISC do solo natural. Este resultado não era esperado, uma vez que nos ensaios de RCNC houve acréscimo de resistência na ordem de 3,6 vezes em relação ao solo puro.

Em decorrência desse comportamento, foram investigadas quais as possíveis variáveis que influenciaram negativamente nos resultados do ISC. Percebeu-se que após o ensaio, ao extrair o solo do cilindro havia uma pequena camada de solo fortemente aderida às superfícies internas do cilindro. Isto indica que houve diluição do aditivo quando o corpo de prova foi imerso em água, anulando seu efeito e ocorrendo uma provável migração para o solo nas bordas do cilindro.

Considerando os resultados obtidos percebe-se que o aditivo analisado pode ser utilizado com vantagem apenas em condições de adequada drenagem. Este é um fator 
limitante, porém, não inviabiliza o uso do aditivo, uma vez que, como destaca Bernucci et al (2006), a condição saturação do solo simulada na imersão em 4 dias no ensaio ISC pode ser excessivamente conservadora.

Conforme o DNIT (2006), um solo para ter aplicação como sub-base deve apresentar ISC superior a $20 \%$. Isto posto, o solo avaliado neste estudo só pode ser utilizado para camadas inferiores à sub-base. Em pavimentos de baixo tráfego e urbanos poderia se admitir que o solo esteja não saturado durante todo o período de projeto. Por outro lado, pode-se estabilizar o aditivo utilizando-o em conjunto com aditivos tradicionais como a cal e o cimento (ECOLOPAVI, 2009).

\section{CONSIDERAÇÕES FINAIS}

Nesta pesquisa foi possível perceber que o aditivo a base de enzimas, na dosagem prescrita nas especificações técnicas do produto, não alterou o parâmetro ótimo de compactação do solo, bem como o teor de umidade ótimo e o peso específico seco máximo. $\mathrm{O}$ aditivo também não propiciou alteração significativa quanto a absorção de água do solo compactado. Porém, notou-se a maior estabilidade do solo com a maior proporção do aditivo.

Quanto à resistência mecânica, o aditivo exerceu a função esperada e elevou a RCNC do solo em estudo, principalmente na maior dosagem analisada, em que foi possível obter um solo com cerca de 3,6 vezes mais resistente do que o solo puro. Em relação ao ISC submerso, houve diluição do aditivo, o que ocasionou a anulação do seu efeito sobre o solo.

Fica demonstrada a potencialidade do uso do aditivo, sendo necessário realizar futuras pesquisas relacionadas à utilização do mesmo no ISC não submerso e em outros tipos de solo da região.

\section{AGRADECIMENTOS}

Os autores agradecem a UNEMAT (Universidade do Estado do Mato Grosso), a Empresa TRANSTERRA e Terraplenagem LTDA por ceder o espaço de laboratório para realização desta pesquisa e a Veneza Comércio e Engenharia LTDA pela doação da amostra do aditivo.

\section{REFERÊNCIAS}

ABNT - ASSOCIAÇÃO BRASILEIRA DE NORMAS TÉCNICAS. NBR 6457: Amostras de solo - Preparação para ensaios de compactação. Rio de Janeiro, 1986. 9p.

.NBR 7182: Ensaios de compactação. Rio de Janeiro, 1986, 10p.

.NBR 9895: Solo - Índice de suporte Califórnia. Rio de Janeiro, 1987, 14p.

.NBR 12770: Solo coesivo - determinação da resistência à compressão não-confinada método de ensaio. Rio de Janeiro, 1996, 4p.

.NBR 13555: Solo-cimento - determinação da absorção d'água. Rio de Janeiro, 1996.

BERNUCCI, L. B.; MOTTA, L. M.; CERATTI, J. A. P.; SOARES, J. B. Pavimentação asfáltica: formação básica para engenheiros. Rio de Janeiro: PETROBRAS: ABEDA, 2006. 504f.

CARMONA, J. P.; OLIVEIRA, P. J. V.; LEMOS, L. J. L. Biocimentation of a Sandy soil with the use of enzymes: effect of some factors. Geotecnia, n.3, p. 3-18, 2017. 
DALLA ROSA, A. E; CRISPIM, F. A. Estabilização mecânica de um solo de Sinop-MT. 2013. 9p. Trabalho de Conclusão de Curso. Universidade do Estado de Mato Grosso. SinopMT.

ECOLOPAVI. Pavimento Ecológico - Manual de pavimentação com solos estabilizados ecologicamente. 2009. 118p.

EUJINE, G. N.; CHANDRAKARAN, S.; SANKAR, N. Accelerated Subgrade Stabilization Using Enzymatic Lime Technique. Journal of Material in Civil Engineering, v. 29, n.9, 2017a.

EUJINE, G. N.; CHANDRAKARAN, S.; SANKAR, N. The engineering behavior of enzymatic lime stabilized soils. Ground Improvement, v. 170, p. 1-11, 2017 b.

JADHAV, G.; PANCHAL, G.; MANE, R. A study on experimental investigation of bioenzyme stabilized expansive soil. In: $5^{\text {th }}$ International Conference on Recent Trends in Engineering, Science \& Management, 2016. Anais... Pune (India): ICRTESM-16, 2016.

MALKO, J. A. C.; CASAGRANDE, M. D. T.; BRAZETTI, R.; ALBUQUERQUE E SILVA, B. Estudo de solos estabilizados com enzima para aplicação em pavimentação. In: XVII Congresso Brasileiro de Mecânica dos Solos e Engenharia Geotécnica, 2014. Anais... Goiânia (Brasil): COBRAMSEG 2014, 2014.

OTP International, Inc. Ficha de Segurança do Material: ESS X. 2013. 1 p. San Diego CA, EUA.

RAFIQUE, U.; NASREEN, S.; NAVEED, R.; ASHRAF, M.A. Application of bioenzymatic soil stabilization in comparison to macadam in the construction of transport infrastructure. Journal of Environmental Biology, v. 37, p. 1209-1215, 2016.

RENJITH, R.; ROBERT, D.; FULLER, A.; SETUNGE, S.; O’DONNELL, B.; NUCIFORA, R. Enzyme based soil stabilization for unpaved road construction. In: The 4th International Conference of Euro Asia Civil Engineering, 2017. Anais... Seoul (South Korea): EACEF2017, 2017.

SAINI, V.; VAISNAVA, P. Soil estabilization by using Terrazyme. International Journal of Advances in Engineering \& Technology, v. 8, p. 566-573, 2015.

SILVA, C. C. Comportamento de solos siltosos quando reforçados com fibras e melhorados com aditivos químicos e orgânicos. 2007. 170f. Dissertação de Mestrado. Setor de tecnologia, Universidade Federal do Paraná. Curitiba, PR.

SIMIONI, C. F. Estudo da estabilização de solos com cal na região de Sinop-MT para fins de pavimentação. 2011. 47f. Trabalho de Conclusão de Curso. Universidade do Estado do Mato Grosso. Sinop, MT. 